\title{
How Regional Trust Cues Could Drive Decentralisation in the Energy Sector-An Exploratory Approach
}

\author{
Tobias Menzel ${ }^{1,2, *(\mathbb{D})}$ and Timm Teubner ${ }^{1,2}$ (D) \\ 1 Trust in Digital Services, Technische Universität Berlin, 10587 Berlin, Germany; teubner@tu-berlin.de \\ 2 Einstein Center Digital Future, 10117 Berlin, Germany \\ * Correspondence: tobias.menzel@campus.tu-berlin.de
}

Citation: Menzel, T.; Teubner, T. How Regional Trust Cues Could Drive Decentralisation in the Energy Sector-An Exploratory Approach. Sustainability 2021, 13, 3010. https://doi.org/10.3390/ su13063010

Academic Editors: Marc A. Rosen and Adam Smoliński

Received: 27 December 2020

Accepted: 3 March 2021

Published: 10 March 2021

Publisher's Note: MDPI stays neutral with regard to jurisdictional claims in published maps and institutional affiliations.

Copyright: (c) 2021 by the authors. Licensee MDPI, Basel, Switzerland. This article is an open access article distributed under the terms and conditions of the Creative Commons Attribution (CC BY) license (https:// creativecommons.org/licenses/by/ $4.0 /)$.

\begin{abstract}
The Green Information Systems research stream was initiated by leading information systems researchers to address climate change through information and communications technology. This paper responds to a call for practical research into the design of information systems that support consumers in their decision making in favour of sustainable products. We apply an exploratory approach to improve understanding of regional trust cues in the energy sector and how these could drive the sector's decentralisation. We explore the still emerging phenomenon of regional text and imagery on digital user interfaces via a multi-method process including quantitative and qualitative content analysis. Our findings suggest that regional energy providers systematically employ regional textual and pictorial trust cues on their websites. We further lay the ground for future experimental work on this matter by defining terms and concepts and systematically capturing design elements. We outline practical implications for designing user interfaces in the energy sector and discuss how this could drive the sector's platformisation and sustainabilisation. In addition, we discuss implications for consumers who could become the target of regional washing attempts, in other words providers applying regional cues to create a regional company image in the absence of actual regionality.
\end{abstract}

Keywords: Green IS; sustainability; decentralisation of the energy sector; interface design; content analysis; regional trust cues

\section{Introduction}

Climate change is a global phenomenon with implications on a local level [1]. Roughly a decade ago, leading scholars in the information systems (IS) community initiated the research field of Green IS to identify solutions to mitigate climate change driven by information and communications technology (ICT) [2-5]. More recently, Koliouska and Andreopoulou suggested in this journal that "all sustainable objectives and targets need ICTs as key catalysts" [6] (p. 4869). Gholami et al. pointed out that "too few information systems [ ... ] academics engage in impactful research that offers solutions to global warming despite the fact that climate change is one of the most critical challenges facing this generation" [7] (p. 521). Most importantly, the community needs to deliver practical and implementable research results that go beyond theory [8].

For the energy sector, this translates into the question of how ICT can contribute to the sector's transition to climate neutrality [2,9]. This transition will require fundamental disruptive shifts towards decarbonisation, decentralisation, and digitalisation [10]. While considerable IS contributions have been provided in recent years on the matters of decarbonisation and digitalisation of the energy sector [9], research on the sector's decentralisation has been less emphasized. Therefore, we set out to contribute to the Green IS debate on the subject of decentralisation of the energy sector with the aim of providing impactful and practical results.

So far, IS research on the decentralisation of the energy sector has mainly focused on the supply of energy (e.g., virtual power plants, decentral generation) or the transmission 
of energy (e.g., smart grids). In contrast, we focus on the demand side and emphasize consumer decision making. Gholami et al. suggest that the design of solutions which "support decision making for more sustainable practices" [7] (p. 527) is an area of research where IS can contribute insights to drive environmental sustainability. In the context of decentralisation in the energy sector, this translates into the question as to how consumers can be supported in making decisions in favour of decentral—or, in other words regionalenergy. The role of consumers in the energy sector is drastically changing and gaining importance [11] as they are evolving from passive consumers to "active energy citizens" [12] (p. 1)-also known as prosumers. Therefore, user-centricity is essential when designing solutions for the future energy sector [13]. Today, in liberalised energy markets the majority of consumer energy plans are sold-and hence, decisions are made-via digital sales channels $[14,15]$. We therefore define energy provider websites as the subject of our study.

When exploring regional energy provider websites, we noticed that these providers frequently use regional textual and pictorial cues (in addition to social and nature cues). An example is provided in Figure 1, which shows a regional energy provider website with a cityscape image of a town within the provider's geographic area of operation. In IS and marketing literature, the use of social cues (e.g., [16]) and nature cues (e.g., [17]) is well established. However, regional cues have to our knowledge not been subject to research in the energy sector and in online contexts. Therefore, the study takes an exploratory approach to shed light on the "surprisingly understudied topic of regionality" [18] (p. 44). Our aim is to increase understanding of the use of regional imagery and text cues on energy provider websites, systematically capturing this new phenomenon in IS research [19], and identifying implications for the design of IS solutions to support decision making in favour of regional energy. We employ the well-established [20] method of content analysis to address this objective and lay the foundation for future quantitative research [21] such as experiments on the behavioural effects of regional cues. This research promises both impactful and practical results thanks to the high usage of these websites and our desire to provide implementable suggestions.

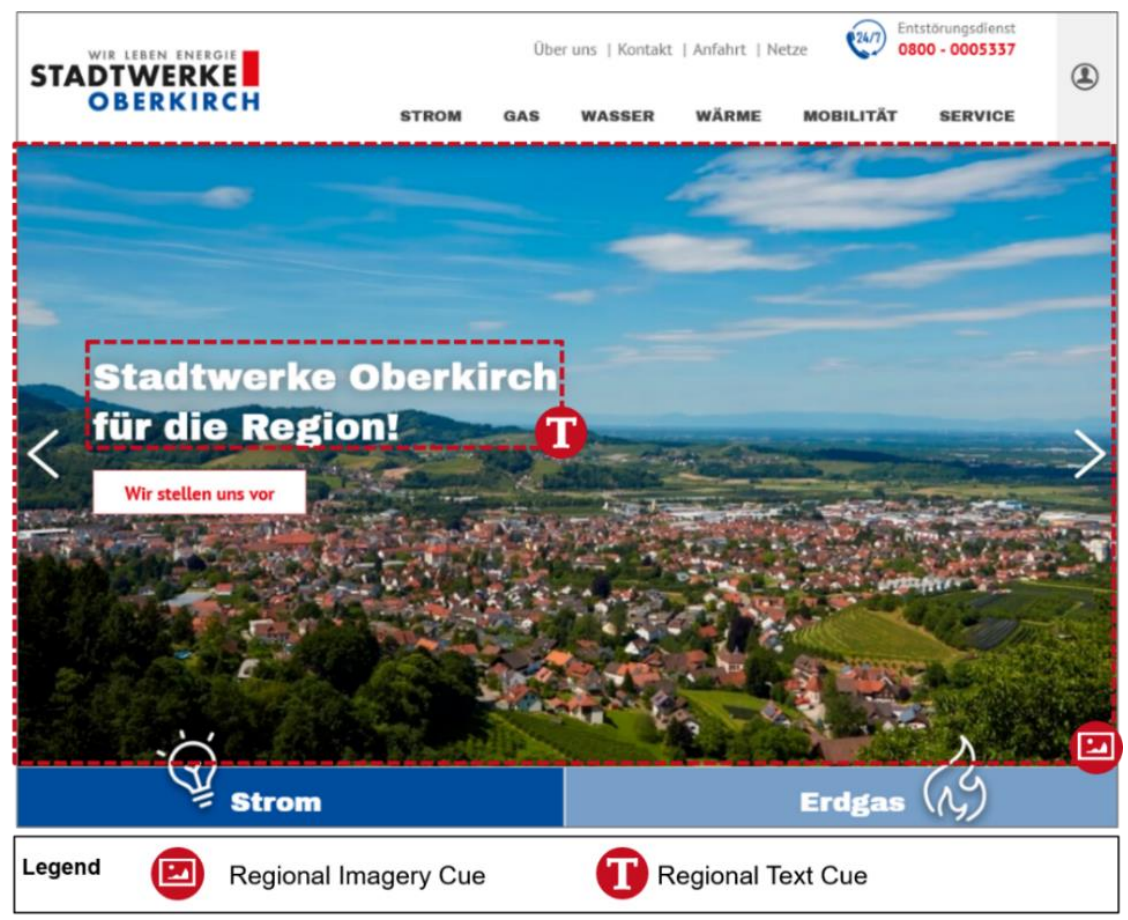

Figure 1. Example of website with regional cues in the form of imagery and text (Translations: Utility of Oberkirch for the region; Source: [S1] in Appendix B). 
For a theoretical framework, we draw on social presence theory [22], biophilia hypothesis [23], and consumer ethnocentrism [24] to develop the construct of regional presence based on the established construct of social presence. The use of imagery and text as trust cues to affect consumer behaviour is well established in marketing and IS literature (e.g., $[16,25,26])$. IS and marketing research has primarily focused on social cues to generate consumer trust and trigger purchase intentions. Social cues on websites generate the perception of "personal, sociable, and sensitive human contact" [16] (p. 410), when, in fact, looking at a website on a screen is characterised by a lack of such contact. For an explanation of this effect, we need to go far back in the evolution of humankind: social cues trigger an evolutionary psychological pattern according to which humans increase their chances of survival through collaboration with other humans [27,28]. In other words, as claimed by Aristotle, humans are social animals [29]. More recently, similar effects have been attested to using nature cues [17]. In similarity to social presence, nature cues generate a perception of the natural environment in the absence of real nature. This again triggers an evolutionary psychological pattern because natural surroundings were critical for human survival as a source of water and nutrition and also provided "security and defence advantages" [30] (p. 19). The biophilia hypothesis is a theory with origins in biology and claims that humans are endowed with an affinity to nature [23]. It explains this behavioural pattern as an "urge to affiliate with nature" [23] (p. 85). The perceived experience of nature reduces stress [30] and restores attention [31] which ultimately turns into positive brand attitude and purchase intention [17]. In a similar fashion, we explain the functionality of regional cues using evolutionary psychology. In the evolutionary logic, human survival depended heavily on a cohesive social group [32]. Following consumer ethnocentrism theory [24], this translates into ethnocentric behaviour on a regional or national level in contemporary consumer decisions. Accordingly, consumers prefer to buy from their ingroup, in other words a (geographically bounded) set of people with which "an individual identifies" [24] (p. 280). Buying from the outgroup "is wrong because [ ... ] it hurts the domestic economy, causes loss of jobs, and is plainly unpatriotic" [24] (p. 280). Based on the similarities with the social presence construct (in other words, the perception of social contact in a human-free setting), we use analogous phrasing for the perception of regionality in an online context that is in fact considered a means of overcoming geographic boundaries [33]. Regional presence can therefore be understood as the sensation of regionality in a set-up characterised by geographic independence. Figure 2 provides a website example in which icons highlight pictorial cues to trigger perceptions of social contact, nature experience, and regionality.

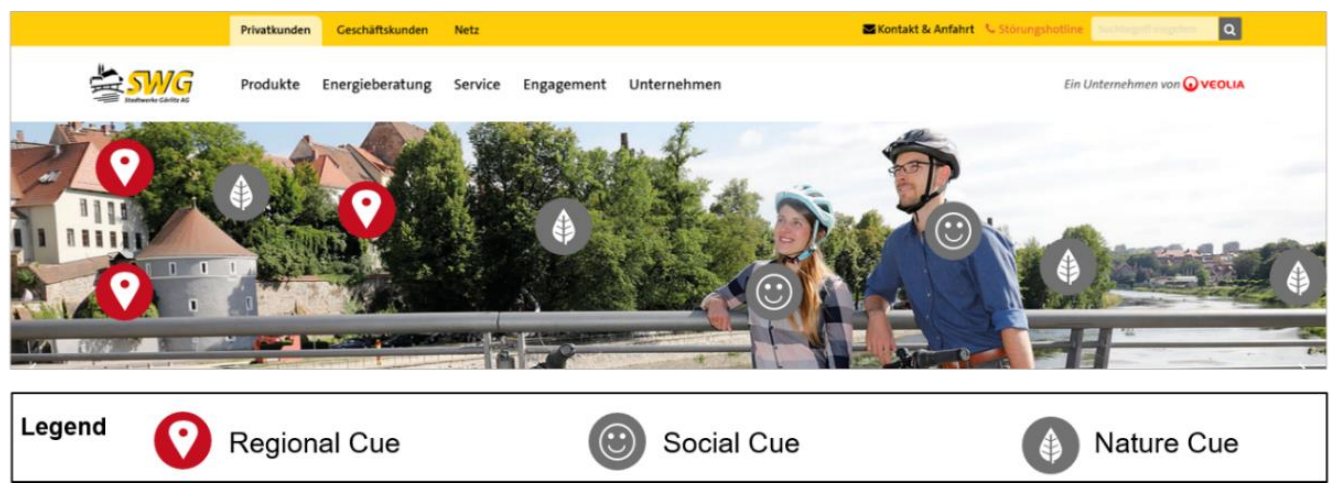

Figure 2. Example of a website with regional, social, and nature cues (Source: [S2]).

The first step in capturing a new phenomenon involves both demonstrating its existence and classifying its major constituent parts [34]. We will therefore put our initial observation on an empirical footing by assessing a sample of energy provider websites. Research Question 1 (RQ1) looks at whether these providers systematically employ regional cues on their websites and, if this is the case, how providers apply these cues-in 
other words, what image motifs and text keywords are used. Because we expect energy providers with a regional operational focus to use regional cues more often, this group is the focus of this first analysis. Hence, our first research question is:

RQ1: Do regional providers systematically apply regional cues on their websites? If so, how are they doing it (i.e., what types of regional imagery and text cues are used)?

We address this question through qualitative content analysis of 318 regional energy provider websites to explore the use of regional, social, and nature cues in a real-life ecommerce use case. We identified the German household electricity market as a compelling object of study since this market is highly fragmented and therefore offers a large sample of companies. In addition, due to the market's genesis, it features an abundance of regional providers whose operations focus is a particular city or region (Stadtwerke). Nevertheless, these providers have been able to sell energy nationwide since market liberalisation in 1998, so their websites target a national audience.

Our analysis addressing RQ1 shows that almost half of the assessed 318 regional energy providers apply regional cues in the form of either text or images on their websites. Primary motifs are cityscapes and buildings, while frequently used textual cues include direct references to a city or region and the terms "region" and "regional." This frequency suggests but does not prove an intentional use of regional imagery and text by regional providers. To validate these findings and provide empirical evidence for this intentionality, we adjust our research design and analyse a second set of 136 provider websites including both regional and national providers. In order to support the hypothesis that regional providers intentionally employ regional cues on their website to outline their offering's regionality, we must identify a significant discrepancy in the use of regional cues between the two groups. Therefore, our second research question is:

RQ2: Do regional providers apply regional cues structurally more often than national providers?

Addressing this question, we examine 136 regional and national energy provider websites by means of quantitative content analysis. We find a significantly higher use of regional text and imagery cues by regional providers through a set of Chi-squared tests. National providers tend to use more nature imagery as well as price and quality text cues. However, discrepancies are not statistically significant.

In addition to these findings, the previously described analysis also provided us with an interesting case study about regionality on user interfaces. Since the use of regional cues is still quite a new phenomenon in the online context, analysing trends may increase our understanding of the direction in which the industry is evolving [35] and provide promising avenues for further research [36]. We therefore conclude this paper with an emerging trend, so our third and final research question is:

RQ3: What is the next trend in the application of regional cues on user interfaces?

To study this question, we describe how a provider tailors its web interface content, including regional imagery and text, to the user's geographic location. This provider appears to possess the tools to trace the location of users when they submit a request to the website and uses this information to adjust the website's imagery and text elements. Apparently, the provider expects that the application of regional cues positively effects user behaviour and provides a compelling template for the application of geo-specific regional references.

The remainder of the paper is structured as follows: Section 2 discusses materials and methods of the three different studies on this matter, while Section 3 outlines their results. In Section 4, we discuss the findings and implications for theorists, practitioners, and consumers. Limitations and future work are discussed in Section 5. Section 6 concludes.

\section{Materials and Methods}

As described above, we performed one study for each research question. In each of the three studies, textual and pictorial cues were assessed as outlined in Table 1 . Study 1 
performs a qualitative content analysis of 318 regional energy provider websites to analyse the use of text and image cues on those websites. In Study 2, we enrich the qualitative investigation with an empirical analysis to test for structural differences in the use of said cues between 65 regional and 71 national providers. We conclude with a case study highlighting the latest trends concerning the use of regional textual and pictorial cues on energy provider websites in Study 3. Using a mixed-method approach provides a greater flexibility in undertaking research and promises better-supported arguments [37].

Table 1. Summary of research designs for RQ1 to 3.

\begin{tabular}{cccc}
\hline & Study 1 & Study 2 & Study 3 \\
\hline Research Question & RQ1 & RQ2 & RQ3 \\
\hline Method & $\begin{array}{c}\text { Qualitative content } \\
\text { analysis }\end{array}$ & $\begin{array}{c}\text { Quantitative content } \\
\text { analysis }\end{array}$ & Case Study \\
\hline Sample & $\begin{array}{c}\text { 318 regional energy } \\
\text { providers }\end{array}$ & $\begin{array}{c}\text { 136 energy providers } \\
\text { (65 regional, 71 national) }\end{array}$ & $\begin{array}{c}\text { 1 national energy } \\
\text { provider }\end{array}$ \\
\hline
\end{tabular}

\subsection{Study 1}

In examining RQ1, we shortlisted 318 regional energy providers from an online resource [38] by selecting corporations (" $A G$ " or " $G m b H$ ") referring to themselves as regional utilities ("Stadtwerke"). Next, we devised a web-scraper to take screenshots of all 318 landing pages (Step 0 in Figures 3 and 4). We analysed the content of these screenshots with different approaches for pictorial and textual cues as described below.

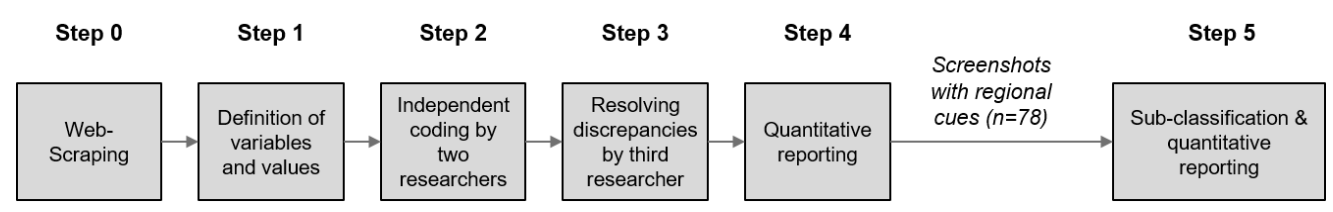

Figure 3. Methodology for analysis of imagery cues.

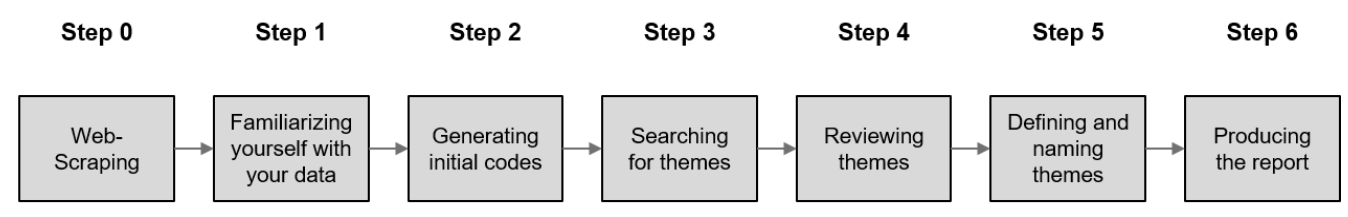

Adapted from Braun \& Clarke (2006)

Figure 4. Methodology for analysis of textual cues.

\subsubsection{Study 1a: Imagery Analysis}

We draw on Bell [39], Callahan [40], Xi et al. [41], and Vilnai-Yavetz and Tifferet [42] to develop the approach illustrated in Figure 3.

- Step 1: Define variables and values: in the first step, it was critical to define explicit and unambiguous categories in order to yield meaningful evidence [39]. In our case, we utilised the three concepts regional, social, and nature and used a binary scale.

- Step 2: Two researchers individually coded the website screenshots following the variables and values defined in step 1 (example provided in Figure 2). We calculated Cohen's kappa [43] to measure inter-rater reliability. With kappa of 0.74 for regional, 0.75 for social, and 0.68 for nature cues, the inter-rater reliability is in the range of substantial agreement [44]. We therefore conclude that the coding provides reliable data and we can proceed with the analysis.

- Step 3: Conflicting cases were resolved by a third researcher. 
- $\quad$ Step 4: Coding results were aggregated and visualised.

- Step 5: For imagery classified as regional, we added two layers of detail by classifying them with regard to their content (e.g., riverside cityscape, church, fountain, sports event, etc.) and structured these subclassifications into the following clusters: cityscapes, buildings, monuments, and bridges.

\subsubsection{Study 1b: Textual Analysis}

Concerning textual cues, we drew on Braun and Clarke [45] and applied their approach for thematic analysis to our context. The approach is outlined in Figure 4.

- Step 1: The textual analysis involved transcribing each website's tag lines. We therefore focused on the three main messages: headline, subtitle, and company slogan. An example is provided in Figure 5. These text fragments were cleansed of noncontextual words.

- Step 2: In the next step, we grouped together words from the same word families (e.g., nature, natural) and with similar meaning (e.g., cheap, low-cost, affordable). We also excluded greetings (e.g., "hello", "welcome") and news items (e.g., "information centre closed during holidays"). Further, we introduced a placeholder ("[city name]") where providers referred to a specific city; this enabled us to track this effect as a pattern.

- Step 3: Building on the results of imagery analysis and related theory, we started off by grouping keywords into social, nature, and regional cues and a general category.

- Step 4: When reviewing step 3, we realised that the remaining keywords could be further grouped and so created two additional clusters for price and quality.

- Step 5: After another round of reviewing keywords, we defined our final set of themes consisting of social, nature, and regional cues as well as price, quality, and a general theme.

- $\quad$ Step 6: For reporting, we aggregated and visualised the findings in a similar way to the approach for imagery. In addition, we generated bar charts with the most frequent key words.

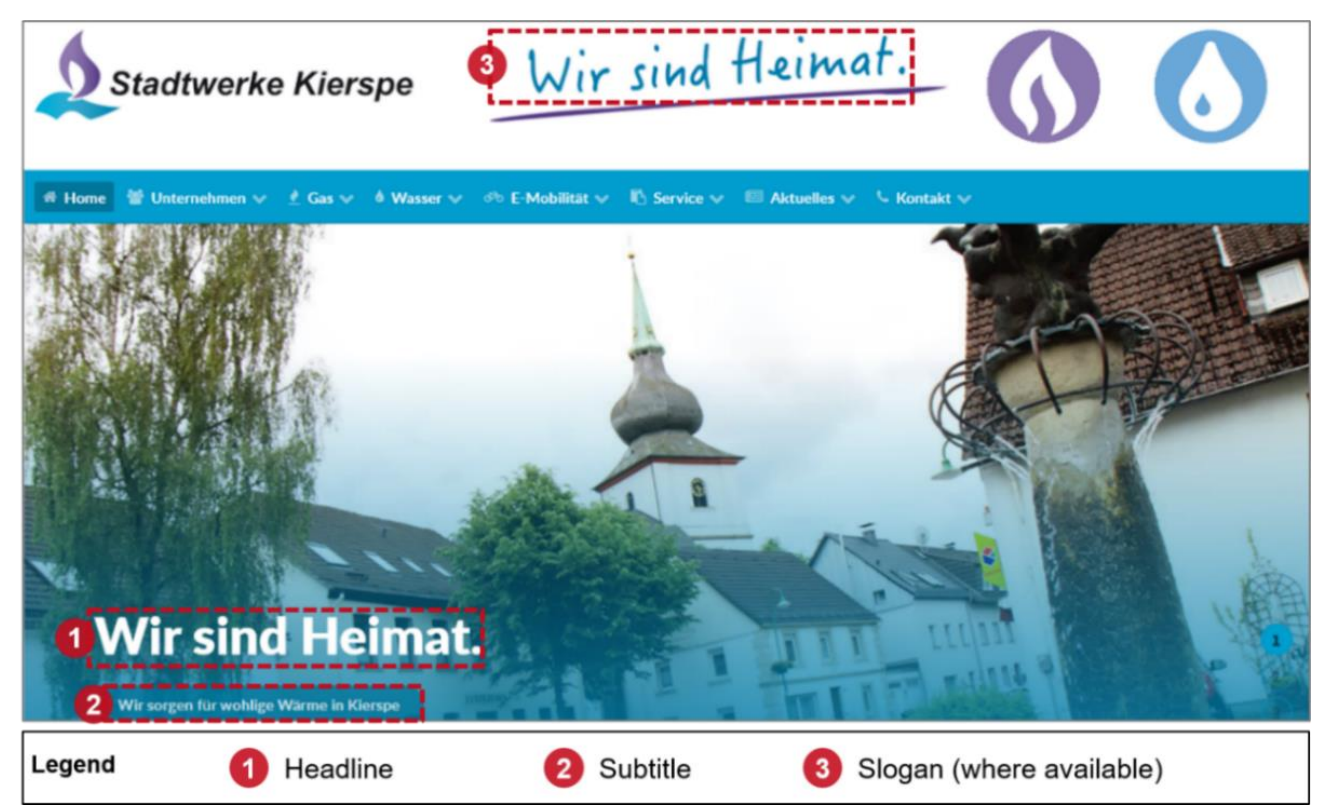

Figure 5. Example of a website where textual areas for transcription are highlighted (Translations: Headline and slogan: We are home; Subtitle: We supply Kierspe with cosy warmth/heat; Source: [S3]). 


\subsection{Study 2}

In addressing RQ2, we generated a set of 136 providers by web-scraping a price comparison portal. Based on how they described themselves (e.g., Stadtwerke, similar to Study 1) and their operational focus, this list was divided into 65 regional and 71 national energy providers. We chose this approach over just expanding the list used in Study 1 for two reasons: focusing on the analysis of providers with sales presence on a comparison portal ensures a certain level of digital savviness of all (and in particular the regional) providers. This would ensure that the selected providers are comparable and hence increase the robustness of the findings. Secondly, using a price comparison portal as a source ensures that all relevant national providers would be included. As these portals represent a significant share of all newly signed household energy contracts [14], this is one of the largest sales channels for energy providers and hence should attract all major players. While national providers might not use specific regional cues (e.g., a specific city name) they can still apply unspecific regional cues such as "regional", "for your city", etc.

In a similar way to the procedure in Study 1, we devised a web-scraper to take screenshots of all 136 provider websites. For imagery, we repeated steps 0 to 4 as described in Study 1. Again, inter-rater reliability for regional cues was in the range of substantial agreement (kappa $=0.74)$. For social cues $(0.94)$ and nature cues $(0.84)$, it was in the range of almost perfect agreement [44]. Textual analysis followed the same steps as described in Study 1 with transcription, cleansing, grouping, and classification. Further, we analysed whether each category's frequency was statistically independent from the provider type (regional vs. national) by means of Chi-squared tests in R. The Chi-squared test evaluates the hypothesis (H0) that the frequency in which regional (and other) cues are used is independent from the provider type. Put in simple terms, H0 claims that there is no relationship between frequency of cues and provider type. Accordingly, rejecting this hypothesis by means of the Chi-squared test provides empirical evidence that the discrepancies in the use of regional (and other) cues is driven by the provider type (H1).

\subsection{Study 3}

Regarding RQ3, we provide a case study on the Greenpeace Energy landing page. We explain how a national provider is using information on the geographic origin of a request to tailor textual and pictorial cues to the user's region. This case study provides a fascinating perspective on the use of regional cues on websites.

\section{Results}

\subsection{Study 1}

Addressing RQ1, we assessed 318 regional energy provider websites by analysing imagery (Section 3.1.1.) and text cues (Section 3.1.2.) used on those sites. This provides insights on how frequently regional providers use regional (and other) cues and offers insights on applied keywords and motifs.

\subsubsection{Study 1a: Imagery}

As displayed in Figure 6, the majority of the energy providers evaluated (215 of 318) employ at least one of the three constructs. Social imagery is the dominant cue (125) but regional (78) and nature (69) imagery are often used. The most frequent combination of cues is regional and nature imagery (27), while only three websites embed imagery combining all three concepts.

Taking a closer look at regional imagery, we identified four clusters of visual motifs (examples provided in Figure 7). Used in more than half of cases (44 out of 78), cityscape was the dominant cluster. Less frequently, providers display buildings (15), monuments (13), and cultural events (6) on their websites. 


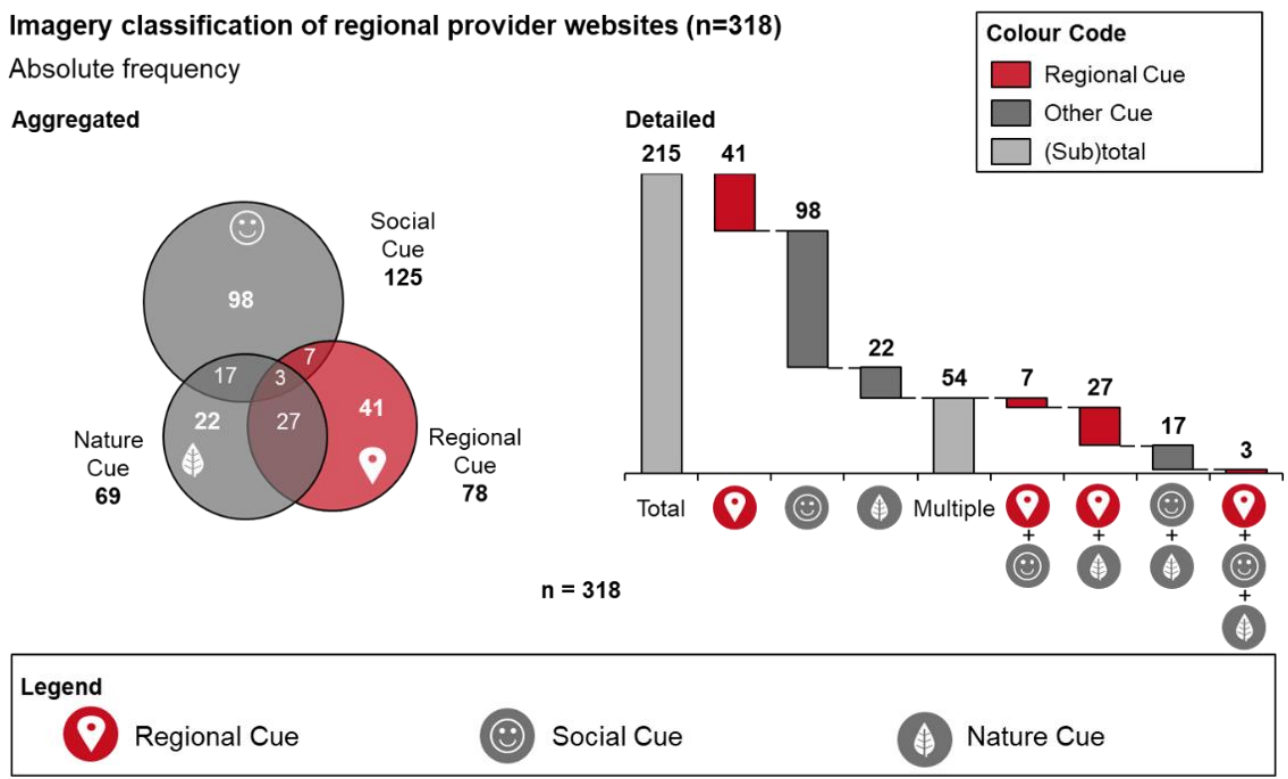

Figure 6. Classification of imagery cues.

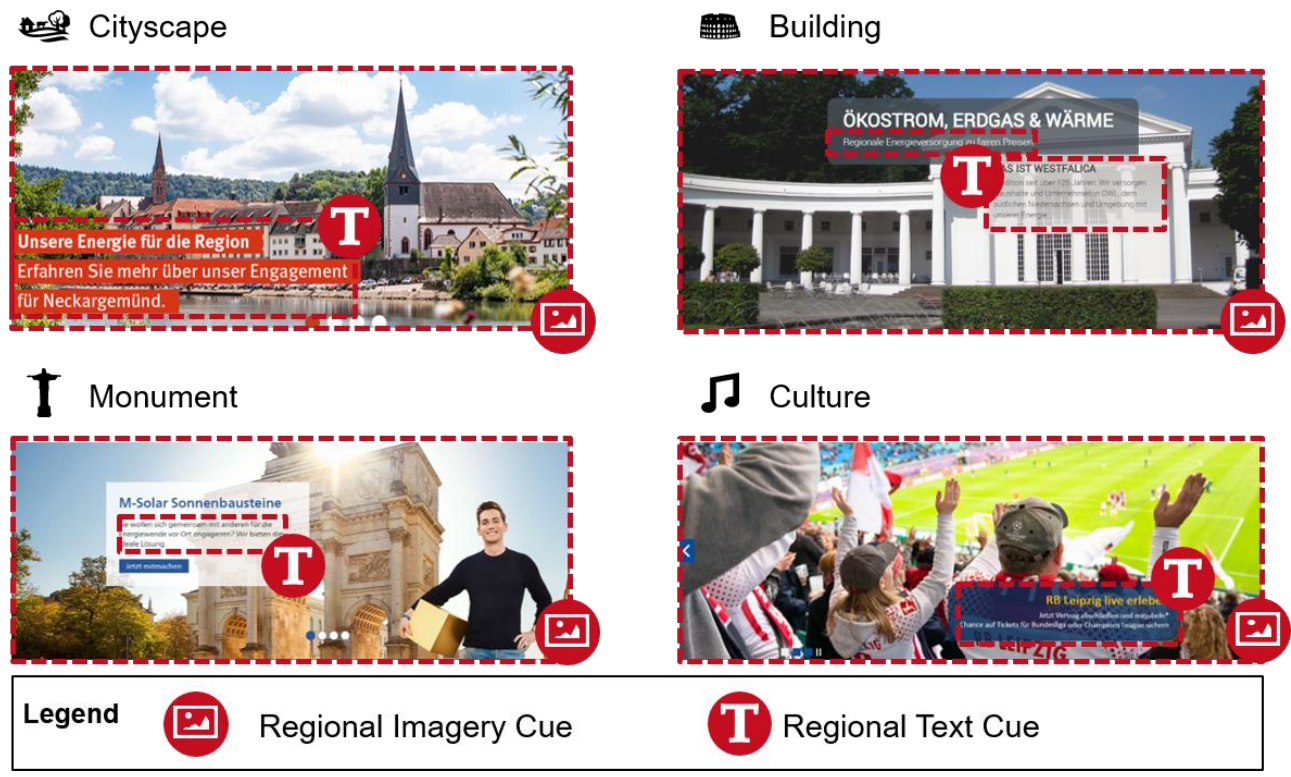

Figure 7. Website examples illustrating types of regional motifs (Translations: Top left: Our energy for the region. Learn more about our commitment to Neckarsgemünd. Top right: Regional energy supply at best price. This is Westfalica. Bottom left: Do you want to get involved with others for your regional energy transition? Bottom right: Experience RB Leipzip live (the regional soccer team); Sources: [S4-S7]).

Within these clusters, there is an additional layer of classification for the main motifs used as a regional cue (frequencies provided in Figure 8). The cityscape concept is mainly represented by aerial photographs of a certain city (25), but riverside panoramas (8) and snapshots of market squares (7) are also frequently used. Providers use churches (4) and secular historic buildings (9) like palaces and castles. The monument cluster comprises towers (5), statues (3), fountains (3), and bridges (2), while culture cues feature either sports (3) or cultural events (3, e.g., concerts, carnival parades). Additional website screenshots with examples for each regional motif are provided in Appendix A. 
Subclassification of regional imagery cues $(n=78)$

Absolute frequency

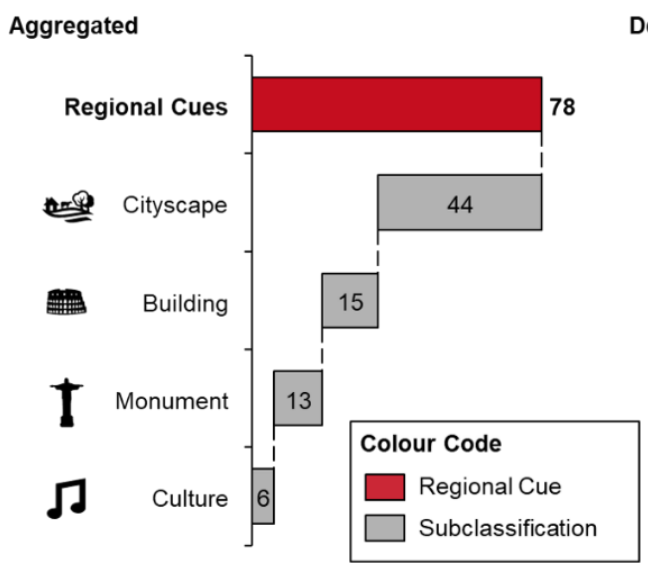

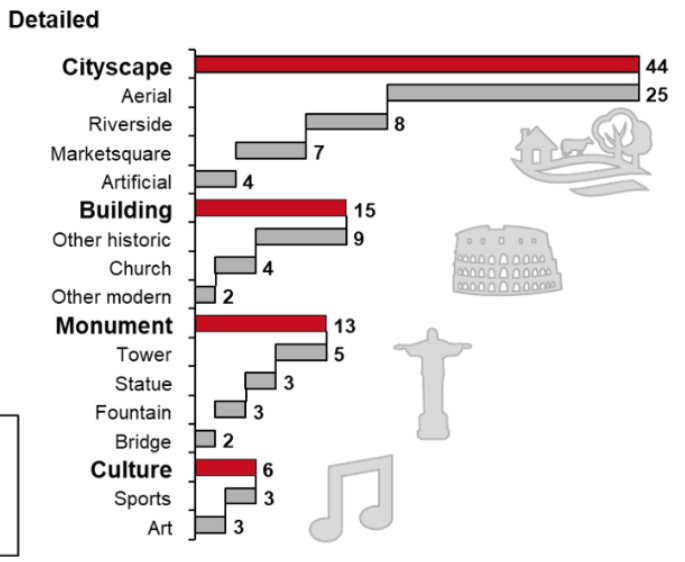

Figure 8. Subclassification of regional imagery cues.

\subsubsection{Study 1b: Text}

Continuing the analysis with a focus on textual cues, we observed an even higher frequency of regional cues (105) on energy provider websites. As shown in Figure 9, almost every third provider applied a textual reference to a city or region on their web interface. In contrast, social (82) and nature (54) cues were less frequently used. The most frequent combination of cues in this context was regional with social keywords (31). We further note that the overall number of providers to use either regional, social, or nature cues or a combination in textual form (174) was lower than the overall number using imagery across those categories (215).

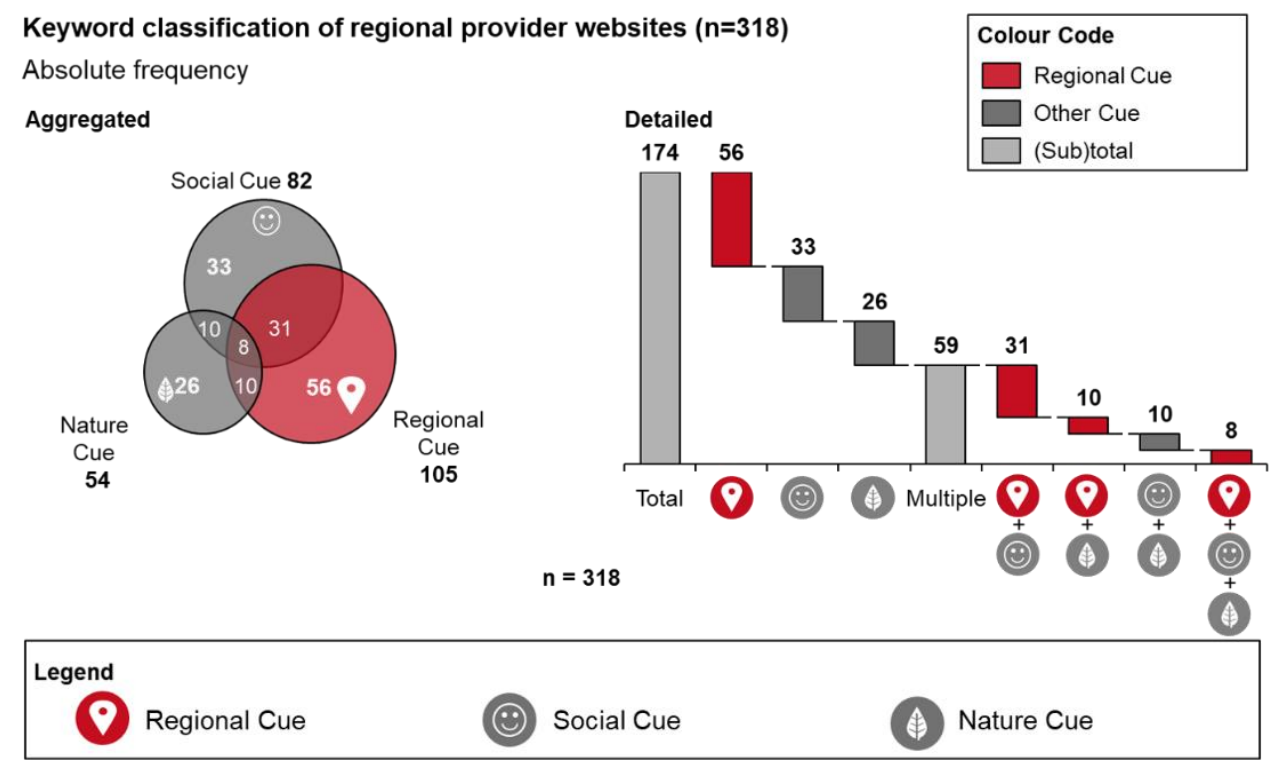

Figure 9. Classification of textual cues.

The fact that less providers use regional, social, and nature cues in textual form compared to imagery might also be explained by the additional possibilities available for text. Alongside regional, social, and nature cues, we introduced price and quality as additional categories in textual analysis. The bar chart in Figure 10 illustrates the 20 most frequent keywords with icons highlighting these five categories. Unsurprisingly, the most often used words are general keywords such as the product sold ("energy": 97 websites; "electricity": 49; "gas": 24) and the provider's name (one of the selection criteria for this list 
of providers was the use of "Stadtwerke" - which means "regional utility" —in the company name). Outside the general category, the most frequent keywords are the regional cues "region" /"regional" (35) and a reference to a particular city or region (27). Frequently mentioned are two keywords with social cues ("for you" /"there for you": 21; "care", 21) and one with nature affiliation ("eco" /"ecological": 17). The most frequent keyword in the price category is "price" /"price stability", (14) while the most frequently used word connoting quality is the term "simple" / "easy" (8, not on the chart).

Top-20 Keywords of regional providers $(n=318)$

Absolute keyword frequency

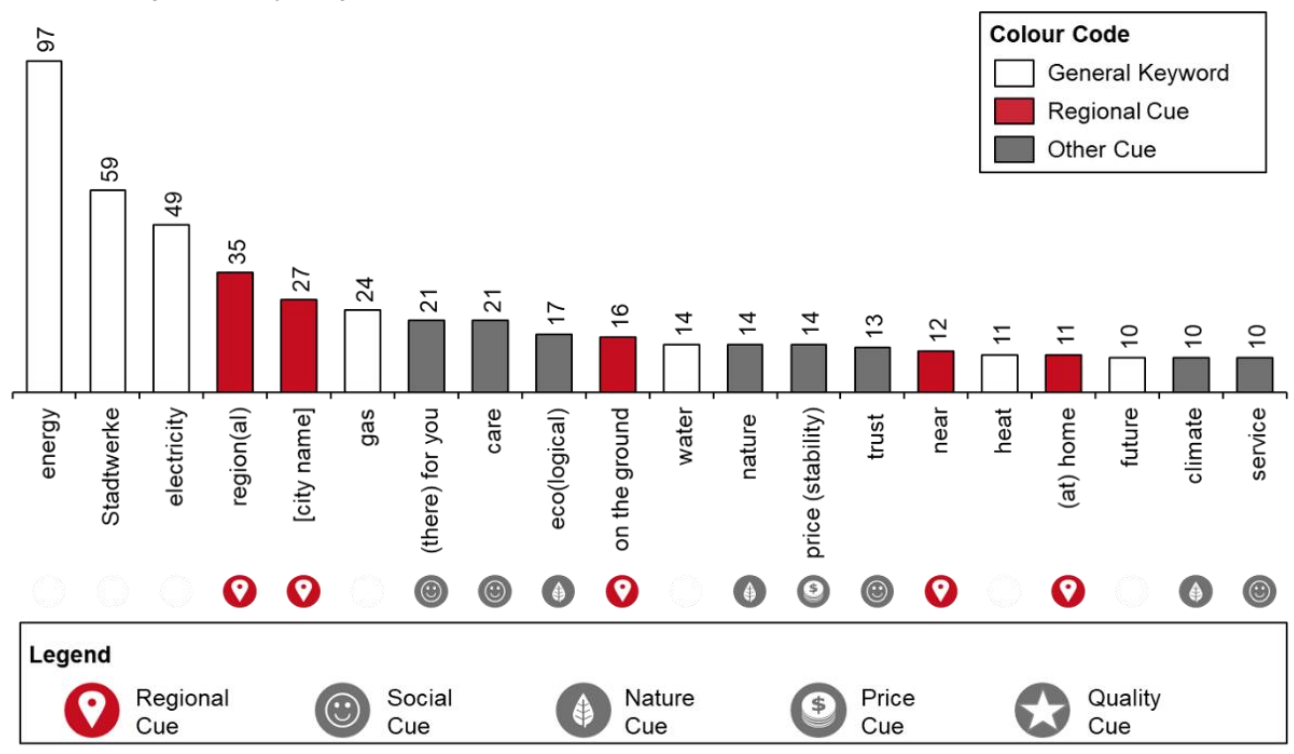

Figure 10. Top 20 most frequent keywords for Study 1 providers.

\subsection{Study 2}

With focus on RQ2, we assessed 65 regional and 71 national energy provider websites to analyse structural differences in the use of regional (and other) trust cues between these provider types. Focusing first on discrepancies in textual cues, Figure 11 shows the relative frequency of keywords used on regional and national provider websites. Notably, regional providers use regional cues most frequently (e.g., a reference to a particular city or region: 25\%; "region" /"regional": 14\%), while national providers tend to emphasise price competitiveness in their messaging (e.g., "low-cost": 20\%; "fair": 9\%; "switch": $9 \%$ ). When using regional cues, regional companies specifically refer to their region (e.g., using the name of their city), while national providers tend to use much more unspecific terms (e.g., "at home", "neighbour", "region" /"regional"). Both provider types embed social and nature cues with similar frequency and employ similar keywords. In fact, the most frequently used keyword in each category is identical for regional and national providers ("there for you" / ffor you" appearing on $8 \%$ of regional provider websites and $9 \%$ of national provider websites; "eco" / "ecological" appearing on $17 \%$ and $13 \%$ of websites respectively).

The empirical analysis of text cues supports these findings (Figure 12). However, only the discrepancy in regional cues is statistically significant $(p<0.01)$ : while almost half of the regional providers (48\%) apply regional text cues on their websites, only $7 \%$ of national providers do so. Although the use of price and quality text cues is considerably lower on regional provider sites (price: $22 \%$; quality: $15 \%$ ) than on national provider websites (price: $35 \%$ of websites; quality: $25 \%$ ), the test statistic fails to reject independence of price $(p=0.12)$ and quality $(p=0.22)$ from the provider type. 
Top-12 Keywords of regional providers $(n=65)$

Relative keyword frequency [\%]

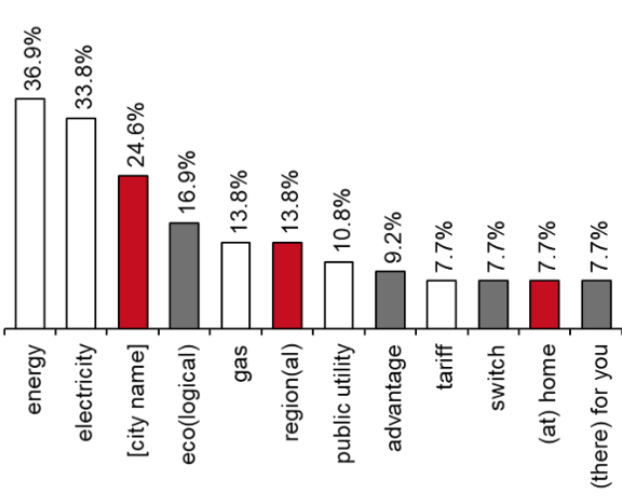

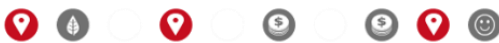

Top-12 Keywords of national providers $(n=71)$

Relative keyword frequency [\%]
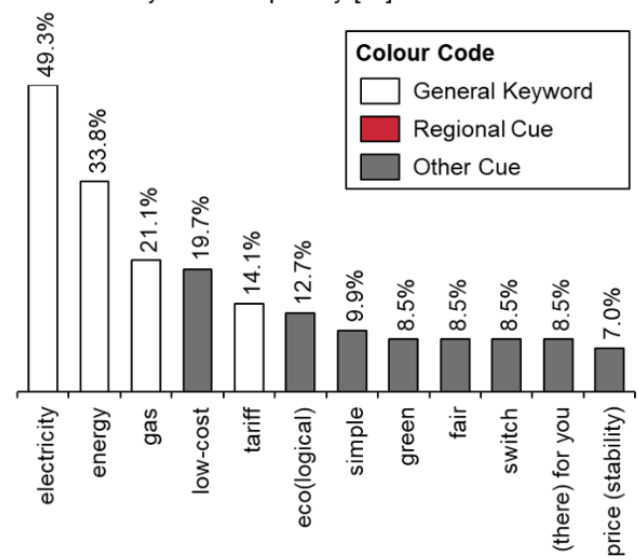

우 0 우 0 우 (우

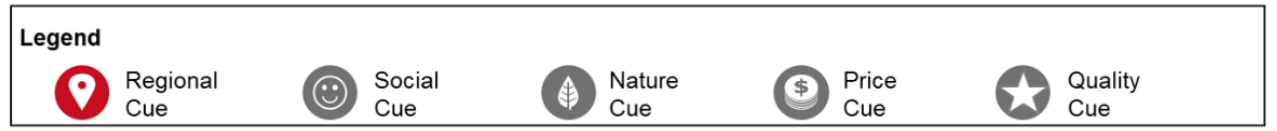

Figure 11. Top 12 most frequent keywords for Study 2 providers.

Comparison of cue frequency on regional and national provider websites

Relative frequency [\%]

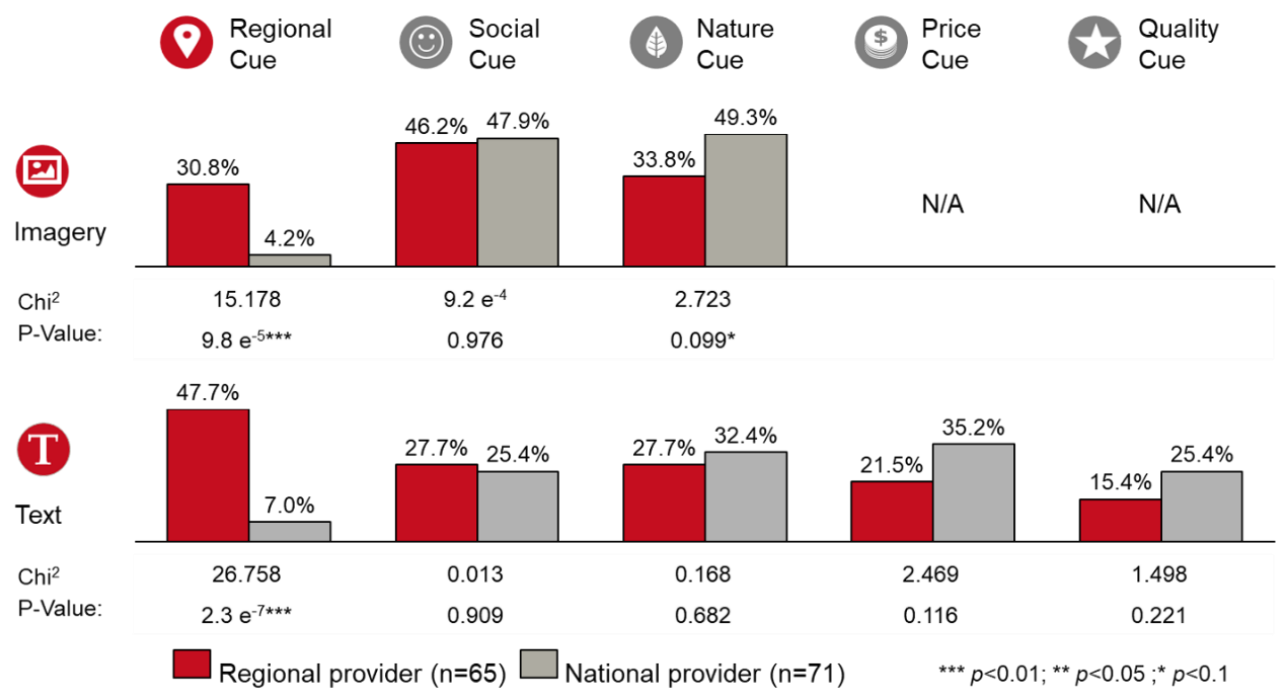

Figure 12. Comparison of relative frequency of imagery and textual cues.

The analysis provides similar results for imagery. Discrepancies in the use of regional cues by regional $(31 \%)$ compared to national providers $(4 \%)$ are statistically significant $(p<0.01)$ and practically relevant. Social cues are used in similar frequencies $(46 \%$ regional; $48 \%$ national). Interestingly, only a third (34\%) of regional providers employ nature cues in their imagery versus half of the national providers $(49 \%)$, which is statistically speaking on the edge of significance $(p=0.099)$.

\subsection{Study 3}

Regarding RQ3, our objective of this study is to highlight upcoming trends in the use of regional trust cues on energy provider websites. During our analysis in Study 2, we noticed that one of the national providers used regional and text cues that were very specific to the researchers' city of residence. This caught our attention because it is counterintuitive 
to our earlier findings. A national provider using regional and text material for a very particular region would limit the effect of those regional cues to that one specific area in Germany. However, their operations are nationwide. We therefore reached out to a network of researchers in different German cities requesting them to go to this provider's website and send us a screenshot. Interestingly, each screenshot contained imagery and textual cues referring to the user's particular city of origin (see examples in Figure 13). This provider appears to be adjusting the website according to user's geographic location (e.g., by locating the IP address). While the overall layout is identical, the background image as well as text fragments within the headline are tailored to the city of origin. For instance, when accessing the website from a Berlin-based internet connection, users see a cityscape image of Berlin with the headline "Good news from the Spree. Berlin goes green", while a website visitor from Hamburg is met with a Hamburg cityscape with the message "Good news from the Elbe. Hamburg goes green" (the Spree and the Elbe are the main rivers in Berlin and Hamburg, respectively). We did not identify a similar provider strategy on any other websites analysed in Studies 1 and 2. We therefore conclude that this seems to be a rather innovative approach which may motivate other providers to follow suit in the near future.
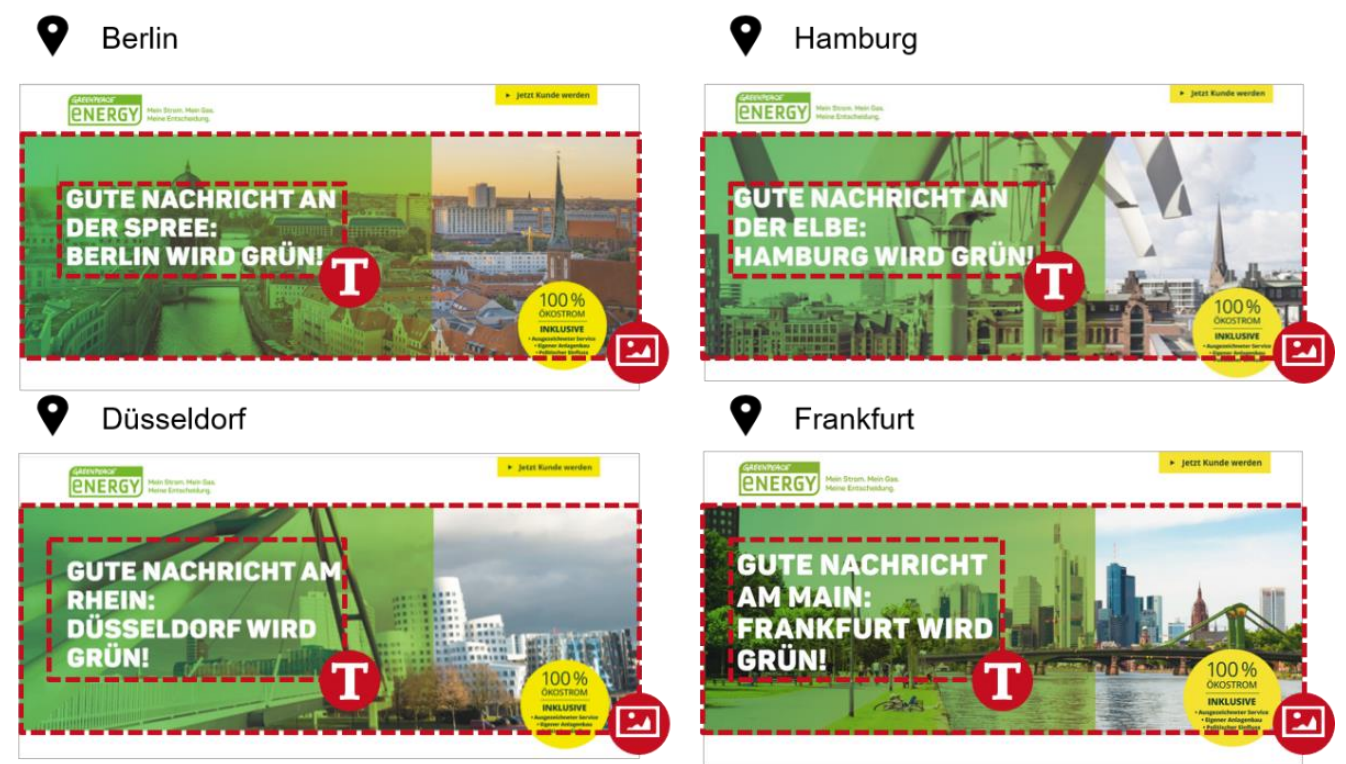

Legend Regional Imagery Cue (T) Regional Text Cue

Figure 13. Website examples with regional cues based on location of web request (Translations: Good news from the Spree/Elbe/Rhine/Main. Berlin/Hamburg/Düsseldorf/Frankfurt goes green". Source: [S8]).

\section{Discussion}

\subsection{Key Findings}

In response to RQ1, we find in Study 1 that almost half of the regional energy providers (47\%) use regional cues in imagery and/or text form on their websites. The fact that the use of regional cues is so frequent suggests that it is an intentional strategy on the part of providers to influence consumer behaviour. When using regional imagery (25\%), we observe a variety of different motifs, with a slight tendency towards cityscapes (in particular from an aerial perspective). A consensus among practitioners on the types of image that best promotes the desired behaviour appears not to have emerged as yet; this is an area where this study could provide useful insights. Regional providers reference regionality at an even higher rate when it comes to textual cues: one in every three websites (33\%) 
features regional text cues. The most frequent keywords are direct references to a city or region and the use of the term "region" / "regional".

Our findings in Study 2 validate these results and also provide empirical evidence that regional providers intentionally employ regional cues on their websites. The relative frequency of regional cues is considerably higher on regional provider websites compared to national provider web interfaces for text $(48 \%$ vs. $7 \% ; p<0.01)$ and imagery cues $(31 \%$ vs. $4 \% ; p<0.01)(\mathrm{RQ} 2)$. Therefore, we conclude that regional providers apply these cues intentionally, expecting positive effects on user behaviour such as trust in providers and purchase decisions.

Moreover, by comparing relative frequencies among the 318 providers in Study 1 (selected based on how they describe themselves) and the 65 regional providers in Study 2 (selected based on a listing on a price comparison platform), we gain insights into how providers' digital savviness may affect their awareness and use of regional cues. This builds on the assumption that a listing on a comparison platform requires certain digital capabilities within the company. We therefore assume that all regional providers in Study 2 have such capabilities at their disposal. Overall, $60 \%$ of regional providers in Study 2 use either regional text or imagery (or both), which is even higher than in Study $1(47 \%)$. Text cues are most significant here ( $48 \%$ vs. $33 \%)$, but imagery cues are also frequent ( $31 \%$ vs. $25 \%)$. We hypothesise that providers with better digital capabilities are either more often aware of the benefits of regional cues or more often capable of implementing these cues on their websites.

Regarding RQ3, we identified a compelling case study demonstrating how providers are taking the use of regional cues to the next level. National providers typically limit themselves to generic regionality cues (e.g., the use of "regional" / "regionality") when operating one website for a nationwide audience. However, Greenpeace Energy has introduced location-specific regional cues tailored to a regional audience. This provides further evidence for our suggestions that providers believe regional cues have a positive effect on user behaviour.

\subsection{Theoretical Contributions}

By analysing the "surprisingly understudied topic of regionality" [18] (p. 44) in the online context, our work has several implications for IS, energy, and marketing research.

First, it responds to calls from leading IS researchers and enriches the discussion on ICT-driven solutions to counter climate change $[2,4,5]$. In particular, we provide tangible implications [8] for the design of user interfaces in the energy sector. By systematically capturing regional imagery and text cues, we enrich the debate on trust cues in the energy sector as a means to "support decision making for more sustainable practices" [7] (p. 527).

Second, while the effects of social cues (e.g., [16,25]) and, to a lesser extent, nature cues (e.g., [17]) on trust and user behaviour are commonly accepted in IS and marketing research, we argue that regional cues should be included in future debates in the field. At first glance, the idea of using regional cues to motivate users' online purchase behaviour may seem somewhat counter-intuitive, because the internet is often considered the "window to the world" [46] (p. 400) and a means of overcoming geographic boundaries [33]. However, our observation of the frequent use of regional cues online suggests otherwise. By deriving the concept of regional presence, we offer a new angle to understand ethnocentric consumer behaviour when interacting with web interfaces. Consumer ethnocentrism theory suggests that consumers prefer purchasing products or services from providers based in the same region as the consumer [24]. We extend this perspective in the sense that already the perception of regionality may cause said provider preference.

Third, we build on the knowledge of regional cues, such as labels [47] and imagery [48] on packaging [49] and offline print advertising [50] and expand on the discussion by (a) applying it to the online context and (b) taking it beyond the food sector. Looking at electricity and gas offers new perspectives compared to the marketing of food products. First, electricity and gas are homogenous and credence goods. This allows us to control for 
potential confounding effects based on product quality. For instance, consumer preference for regional strawberries (i.e., those produced in geographic proximity to the consumer) may be driven by freshness more than anything else. In contrast, it is impossible for consumers to distinguish regional from non-regional electricity or gas as they are physically identical at the point of consumption. Second, electricity and gas are supplied through networks. This eliminates the transportation cost effect since network fees are charged to consumers regardless of the product's geographic origin. For these two reasons, we assume that any observed user preferences for regional products in this context are purely driven by the very idea of regionality.

Fourth, in terms of methodology we enhanced the content analysis toolbox by combining two quantitative approaches: using Chi-squared tests to assess statistical differences in the frequency of motifs used on websites (e.g., [51]) and analysing differences in the use of website content across two provider types (e.g., [42]).

\subsection{Practical Implications}

Considering practical implications, our study yields new insights for the design of user interfaces in the energy sector. The role of regional products and services is of particular importance in the energy segment since decentralisation is one of three major disruptions (alongside digitisation and decarbonisation) that the industry needs to undergo in order to live up to climate policy ambitions [10]. In the narrower context of provider websites, a well-designed user interface is important for energy providers as their websites are one of their major sales channels [15]. In a broader context, the rise of the platform economy in the energy sector creates a need for trust-building user interfaces in the coming years [52]. New platform technologies such as peer-to-peer local energy markets [53], plugsharing platforms [54], and vehicle-to-grid solutions [55] will become more important in the energy sector and are projected to play a pivotal role in its decarbonisation, digitisation, and decentralisation [52]. However, for these new technologies to be adopted quickly by consumers, trust-building user interfaces will be key (e.g., [56]) because trust in the (energy) provider is a critical driver for IS adoption [57-59].

Regarding the implementation of regional cues on websites and other user interfaces, a new challenge arises for operators. While social and nature cues can be generically applied, regional cues need to be adjusted according to the physical location of the website user. For instance, a picture of a scenic landscape will trigger similar effects for users in City A and City B, but a picture of the market square in City A may not resonate equally well with users located in City B. The provider must therefore determine how best to ascertain user location. We briefly discuss the advantages and limitations of four approaches:

- IP address: Potentially the simplest way is to use IP addresses, but this has significant constraints. For instance, if users employ VPN tunnels, their IP addresses and locations are not aligned. In addition, in cases where users make purchases online while at work or away from home, a regional cue based on the user's IP address will produce flawed results.

- Cookies: Cookies might provide a more accurate estimate of geographic location, but they are often limited by user privacy settings.

- User data provided during customer journey: A third option is to collect user data directly. For instance, the shipping or billing address provided during an online shopping process should be a precise estimate of the user location. However, such information is often only provided after the purchase decision has been made.

- User profile data: A final option is to use profile data. In particular in platform solutions, providers encourage users to create profiles which typically include geographic details. These details should provide a sound basis for tailoring regional cues to the user. However, this option is also limited to customers deciding to set up a user profile.

In summary, none of the options mentioned are perfect, and the decision as to whether the advantages outweigh the limitations will depend on the specific application. 


\subsection{Consumer and Policy Implications}

While the previous section looked at how consumers could be supported in their decision making in favour of regional products, an improved understanding of regional trust cues could also yield negative consequences for consumers: providers could use regional trust cues to deceive consumers through regional washing. We derive this term from the idea of "green washing", which is defined as "[companies] misleading consumers about their environmental performance or the environmental benefits of a product or service" [60] (p. 64). Analogously, non-regional providers could regionally wash their company image; in other words, they could use regional trust cues to deceive consumers regarding their regionality and decentralisation.

Since beginning our research, we have observed such regional washing approaches on user interfaces in the energy sector. In Figure 14, we provide two examples of national suppliers using regional cues to encourage customers to purchase decentrally produced energy - one provider merely pretends to be regional (Regionale Energiewerke, on the left in the figure), while the other backs up their claims with actions (enyway, on the right).

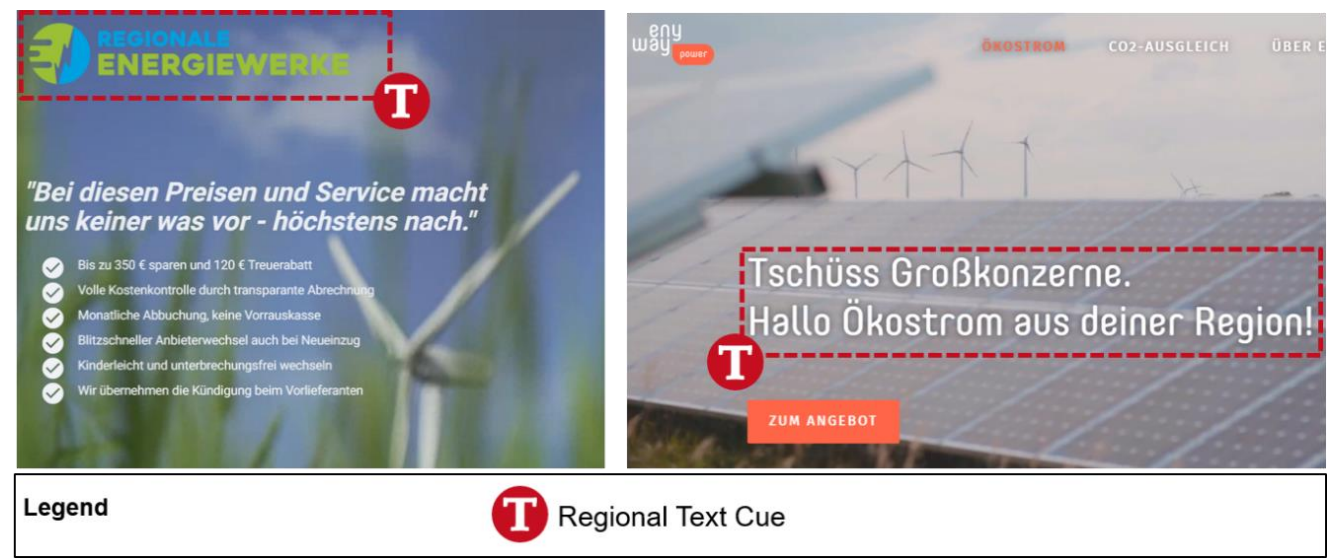

Figure 14. Website examples of national providers with regional cues (Translations: Left: Regional Utility. Right: Goodbye corporates. Hello eco power from your region; Sources: [S9, S10]).

- Regionale Energiewerke [61] (left in Figure 14): This is an example of regional (and also green) washing because the company uses both regionality and sustainability to promote itself on its website but does not substantiate these claims. First, the company name contains the German word for regional and the term "Energiewerke", which mirrors the phrasing of the German term "Stadtwerke" ("regional utilities"). Second, they use nature imagery to signal ecological sustainability on the website. Third, in the text on their website, they describe themselves as a "regional energy provider", a company that "stands for sustainability" and that their energy plans are "environmentally aware" [61] (p. 1). However, following the customer journey to purchase an energy plan shows that the company does not offer energy from renewable sources. The company also has none of the attributes of a typical regional energy provider (e.g., operational focus on a region, public ownership by a municipality or region, historical genesis in a region). Their claims of regionality and sustainability are therefore a marketing strategy that is not supported by corporate behaviour. Both consumers and key policy makers need to be aware of this evolution.

- Enyway [62] (right): In contrast, an example of how regional cues can encourage customers to purchase regional energy is provided by the firm enyway. The marketing claim of enyway promotes decentralisation in the energy sector in multiple ways. Firstly, the phrase "ecological electricity from your region" [62] (p. 1) promotes decentralisation through regional energy generation. Secondly, the phrase "Goodbye corporations" [62] (p. 1) suggests an interpretation of decentralisation as a shift away from large, centralised providers to smaller regional companies. Enyway's claims are 
backed up by its activities. The company's business model is to provide a platform that matches residential energy generators (e.g., rooftop PV plants, small farmers with wind turbines, etc.) with household consumers in their region.

In terms of mitigation strategies, research on green washing suggests increased transparency, ethical leadership, and employee trainings [60]. Other scholars propose ecolabels [63]. These approaches could be adapted to the regional washing context as well.

\section{Limitations and Future Work}

This paper is of course not without limitations. First and most importantly, we have analysed provider behaviour by analysing their websites. Our findings suggest that the evaluated providers assume that using regional imagery will have positive effects on customer behaviour (e.g., trust in the provider and purchases). However, this does not necessarily imply that consumers are actually affected by regional cues and, if so, whether they are affected in the way that providers intend. Therefore, further research should shift focus and assess the effects of regional cues on consumer behaviour. We have in this study defined terms and concepts and systematically captured design elements as a foundation for future work. More specifically, we propose three methodologies and briefly discuss advantages and limitations.

- Online experiment/survey: An online experiment could assess how perceived regionality affects trust and purchase intentions. This approach would enable a large sample size and a wide range of control variables. However, only intentions and not actual behaviour could be captured.

- Eye tracking experiment: Eye tracking offers the analysis of cognitive processes of participants by analysing their eye movement and hence offers a substantial addition to insights gained in a survey. However, for practical reasons the sample would generally be limited. The experiment also takes place in a laboratory set-up and hence does still not reflect actual purchase settings.

- A/B testing field experiment: In cooperation with an energy provider, research findings should be tested in a field experiment. This could be implemented by means of A/B testing and would provide data on real consumer decisions. However, A/B testing in a live environment provides fewer options to gain control variables.

We propose a combination of these methods for future work.

Second, the link between the energy sector's decentralisation and consumer decisions in favour of regional providers hinges on the fact that these providers produce the energy in that region. This is typically the case for regional energy providers (e.g., with waste-to-energy plants) and the share of regionally generated energy is increasing with the expansion of renewable energy technologies. In particular, regional providers are increasingly investing in onshore wind and solar plants within their area of operation. Nevertheless, other examples exist as we have shown in Section 4.4, and this aspect should be considered in future work.

\section{Conclusions}

Motivated by the need for ICT-driven solutions to fight climate change, this study offers an exploratory analysis of the use of regional trust cues on user interfaces in the energy sector. The application of regional trust cues on user interfaces in the energy sector could motivate consumers to purchase regional energy products. Decision making in favour of more regional energy providers would accelerate decentralisation in the energy sector and avoid expensive and unpopular power grid expansions. We performed qualitative and quantitative content analysis of energy provider websites. Our findings highlight the relevance of this emerging phenomenon and provide a groundwork for future experimental research by providing terms, concepts, and a theoretical foundation. Further, we contextualised our work within the theoretical conversations around visual trust cues in the IS community as well as text and imagery in regional offline marketing. 
We drew conclusions for the design of user interfaces in the energy sector and outlined technical approaches that tailor regional cues to the user's geographical location. Next, we explained how providers are using these cues to give an impression of regionality, and we presented strategies to mitigate such examples of regional washing. Last, we pointed to future avenues of research by outlining three potential study methodologies for analysing the behavioural effects of regional trust cues.

Author Contributions: Conceptualization, T.M. and T.T.; methodology, T.M. and T.T.; software, T.T.; validation, T.M. and T.T.; formal analysis, T.M.; investigation, T.M. and T.T.; resources, T.M. and T.T.; data curation, T.M.; writing—original draft preparation, T.M.; writing—review and editing, T.M. and T.T.; visualization, T.M.; supervision, T.T.; project administration, T.M. and T.T.; funding acquisition, T.M. All authors have read and agreed to the published version of the manuscript.

Funding: We acknowledge support by the German Research Foundation and the Open Access Publication Fund of TU Berlin, who funded this article's processing charges.

Institutional Review Board Statement: Not applicable.

Informed Consent Statement: Not applicable.

Data Availability Statement: The data to support the findings of this study is available from the corresponding author upon reasonable request.

Acknowledgments: We thank Thanh Ngo Chi for his support in coding the imagery.

Conflicts of Interest: The authors declare no conflict of interest.

\section{Appendix A. Additional Website Examples}

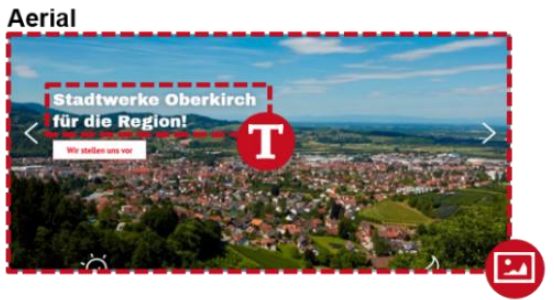

Market square

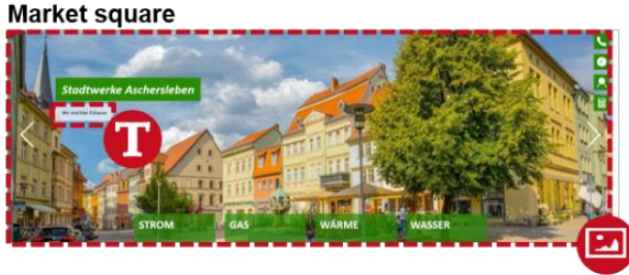

Legend
Regional Imagery Cue

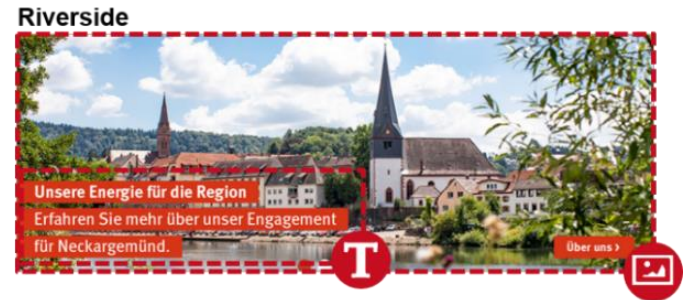

Artificial

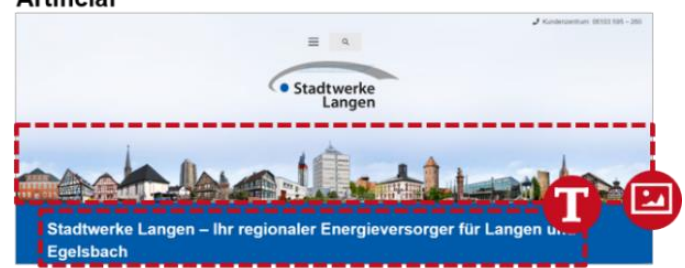

I Regional Text Cue

Figure A1. Regional imagery website examples: Cityscapes (Sources: [S1, S4, S11, S12]). 

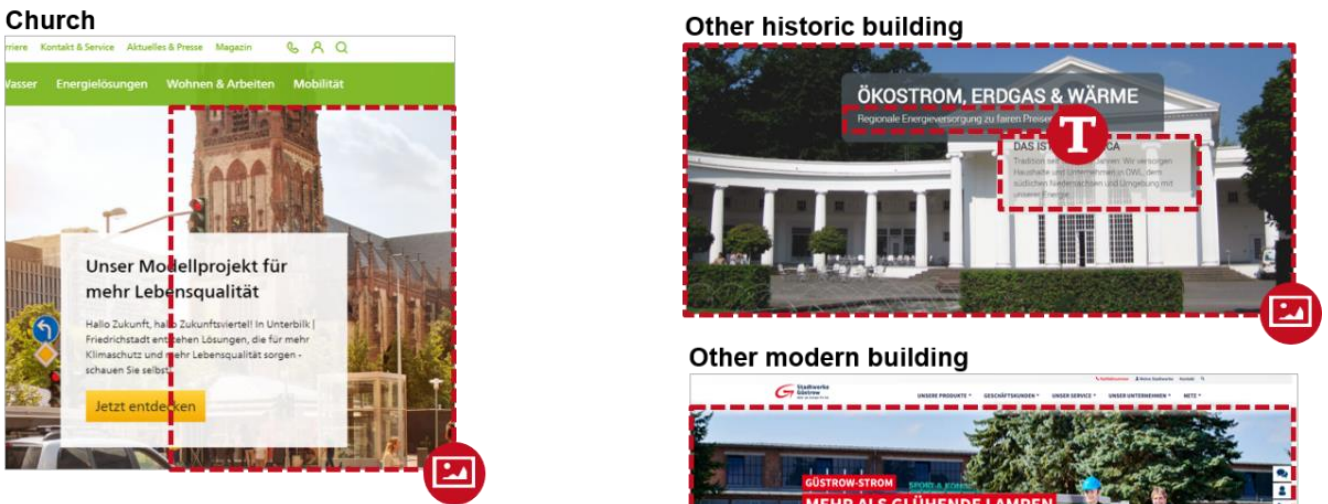

Other modern building

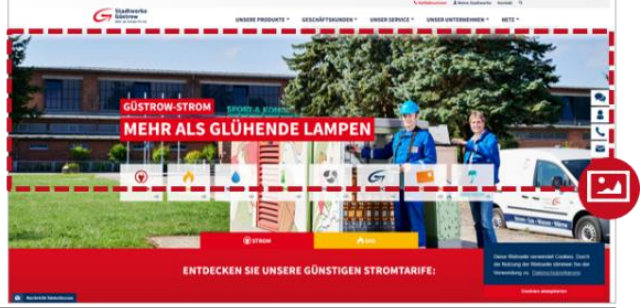

Legend Regional Imagery Cue

Regional Text Cue

Figure A2. Regional imagery website examples: Buildings (Sources: [S5, S13, S14]).
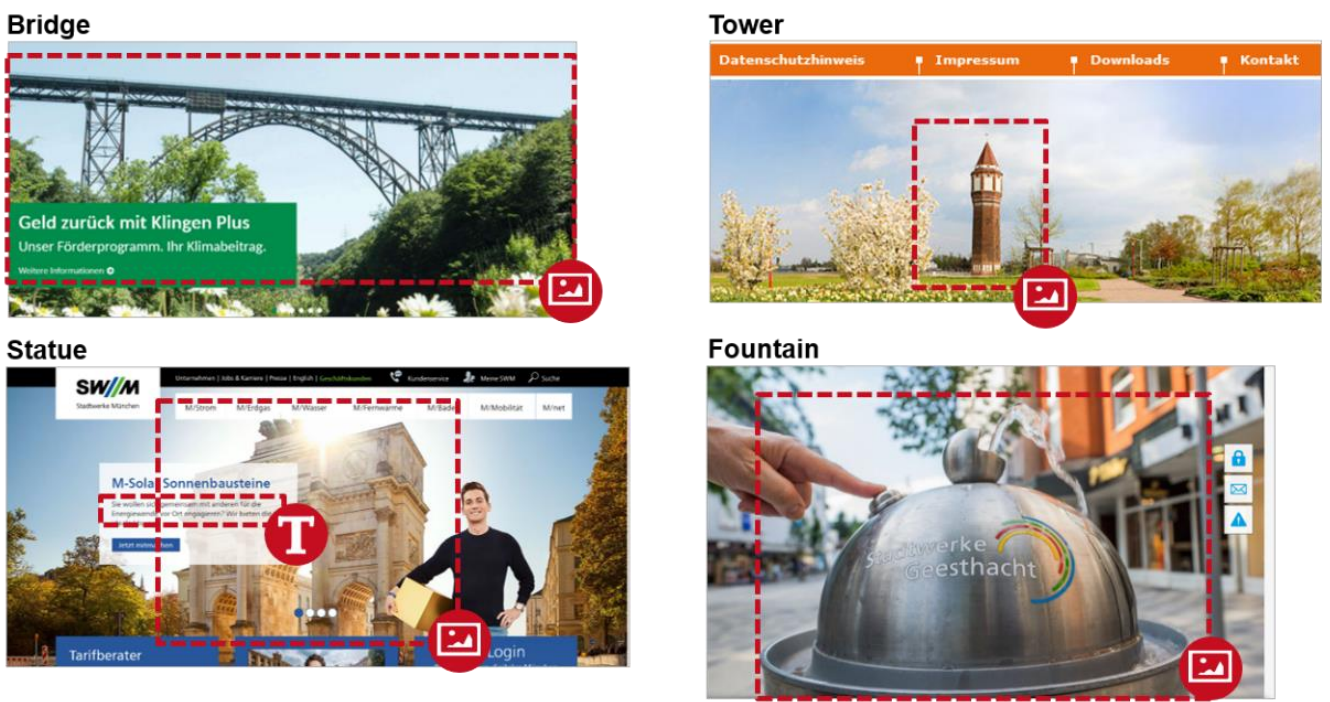

Legend Regional Imagery Cue Regional Text Cue

Figure A3. Regional imagery website examples: Monuments (Sources: [S6, S15-S17]).
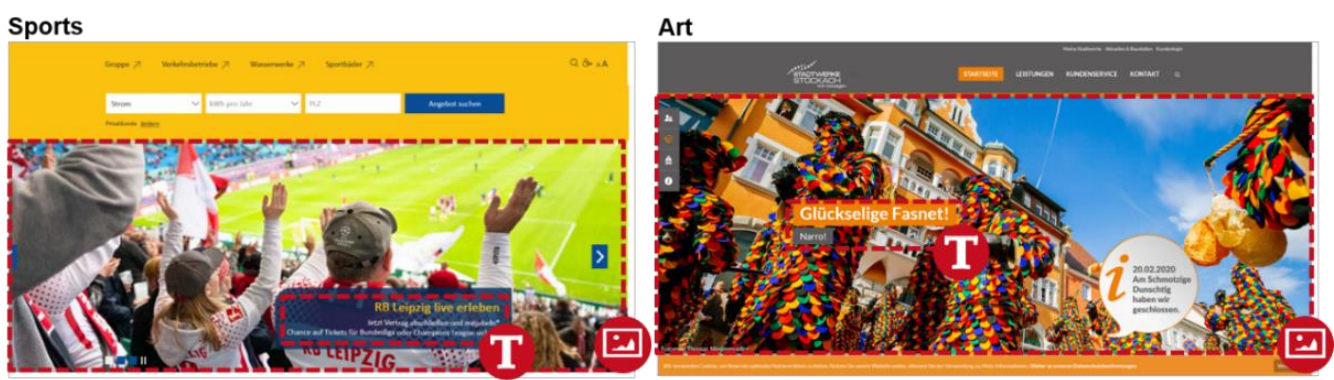

Legend Regional Imagery Cue T Regional Text Cue

Figure A4. Regional imagery website examples: Cityscapes (Sources: [S7, S18]). 


\section{Appendix B. Sources for Website Screenshots}

S1. Stadtwerke Oberkirch. Available online: https://www.stadtwerke-oberkirch.de/ (accessed on 16 February 2021).

S2. Stadtwerke Görlitz. Available online: https:/ /www.stadtwerke-goerlitz.de/privatkunden/ (accessed on 5 November 2020).

S3. Stadtwerke Kierspe. Available online: https://stadtwerke-kierspe.de/ (accessed on 5 November 2020).

S4. Stadtwerke Neckargemünd. Available online: https:/ / www.stadtwerke-neckargemuend. de/ (accessed on 5 November 2020).

S5. Westfalica Stadtwerke. Available online: https://www.westfalica.de/privatkunden (accessed on 5 November 2020).

S6. Stadtwerke München. Available online: https://www.swm.de/ (accessed on 5 November 2020).

S7. Leipziger Stadtwerke. Available online: https://www.l.de/stadtwerke/\# (accessed on 5 November 2020).

S8. Greenpeace Energy. Available online: https://www.greenpeace-energy.de/privatkunden. $\mathrm{html}$ (accessed on 5 November 2020).

S9. Regionale Energiewerke. Available online: https://regionale-energiewerke.de/home (accessed on 10 November 2020).

S10. Enyway. Available online: https://www.enyway.com/de/power (accessed on 10 November 2020).

S11. Stadtwerke Aschersleben. Available online: https://www.sw-aschersleben.de/startseite. html (accessed on 10 November 2020).

S12. Stadtwerke Langen. Available online: https:/ /stadtwerke-langen.de/ (accessed on 10 November 2020).

S13. Stadtwerke Düsseldorf. Available online: https:/ /www.swd-ag.de/ (accessed on 10 November 2020).

S14. Stadtwerke Güstrow. Available online: https://www.stadtwerke-guestrow.de/ (accessed on 10 November 2020).

S15. Stadtwerke Solingen. Available online: https://www.stadtwerke-solingen.de/privatgewerbekunden/kundenservice/foerderprogramm-klingen-plus/haushalt/ (accessed on 10 November 2020).

S16. Stadtwerke Lehrte. Available online: https://www.stadtwerke-lehrte.de/ (accessed on 10 November 2020).

S17. Stadtwerke Geesthacht. Available online: https:/ /www.stadtwerke-geesthacht.de/ startseite (accessed on 10 November 2020).

S18. Stadtwerke Stockach. Available online: https:/ /www.stadtwerke-stockach.de/startseite. html (accessed on 10 November 2020).

\section{References}

1. Borowski, P.F. Nexus between water, energy, food and climate change as challenges facing the modern global, European and Polish economy. AIMS Geosci. 2020, 6, 397-421. [CrossRef]

2. Watson, R.T.; Boudreau, M.-C.; Chen, A.J. Information Systems and Environmentally Sustainable Development: Energy Informatics and New Directions for the IS Community. MIS Q. 2010, 34, 23-38. [CrossRef]

3. Dedrick, J. Green IS: Concepts and Issues for Information Systems Research. Commun. Assoc. Inf. Syst. 2010, 27, 173-184. [CrossRef]

4. Melville, N.P. Information Systems Innovation for Environmental Sustainability. MIS Q. 2010, 34, 1-21. [CrossRef]

5. Malhotra, A.; Melville, N.P.; Watson, R.T. Spurring Impactful Research on Information Systems for Environmental Sustainability. MIS Q. 2013, 37, 1265-1274. [CrossRef]

6. Koliouska, C.; Andreopoulou, Z. A Multicriteria Approach for Assessing the Impact of ICT on EU Sustainable Regional Policy. Sustainability 2020, 12, 4869. [CrossRef]

7. Gholami, R.; Watson, R.T.; Hasan, H.; Molla, A.; Bjørn-Andersen, N. Information Systems Solutions for Environmental Sustainability: How Can We Do More? J. Assoc. Inf. Syst. 2016, 17, 521-536. [CrossRef]

8. Brocke, J.V.; Watson, R.T.; Dwyer, C.; Elliot, S.; Melville, N. Green Information Systems: Directives for the IS Discipline. Commun. Assoc. Inf. Syst. 2013, 33, 30. [CrossRef] 
9. Goebel, C.; Jacobsen, H.A.; del Razo, V.; Doblander, C.; Rivera, J. Energy Informatics: Current and Future Research Directions. Bus. Inf. Syst. Eng. 2014, 6, 25-31. [CrossRef]

10. Di Silvestre, M.L.; Favuzza, S.; Sanseverino, E.R.; Zizzo, G. How Decarbonization, Digitalization and Decentralization are changing key power infrastructures. Renew. Sustain. Energy Rev. 2018, 93, 483-498. [CrossRef]

11. Borowski, P.F. Zonal and Nodal Models of Energy Market in European Union. Energies 2020, 13, 4182. [CrossRef]

12. Campos, I.; Pontes Luz, G.; Marín González, E.; Gährs, S.; Hall, S.; Holstenkamp, L. Regulatory Challenges and Opportunities for Collective Renewable Energy Prosumers in the EU. Energy Policy 2020, 138, 111212.

13. Immonen, A.; Kiljander, J.; Aro, M. Consumer viewpoint on a new kind of energy market. Electr. Power Syst. Res. 2020, 180, 106153. [CrossRef]

14. YouGov. Comparison Check Energie 2015; YouGov: Cologne, Germany, 2015.

15. Dringenberg, H. Interview with Horst Dringenberg; Kearney: Chicago, IL, USA, 2020.

16. Gefen, D.; Straub, D.W. Consumer trust in B2C e-Commerce and the importance of social presence: Experiments in e-Products and e-Services. Omega 2004, 32, 407-424. [CrossRef]

17. Schmuck, D.; Matthes, J.; Naderer, B.; Beaufort, M. The Effects of Environmental Brand Attributes and Nature Imagery in Green Advertising. Environ. Commun. 2017, 12, 414-429. [CrossRef]

18. Herz, M.; Diamantopoulos, A. Deceptive Use of the 'Regionality' Concept in Product Labelling: An Abstract. In Proceedings of the 22nd AMS World Marketing Congress, Edinburgh, UK, 9 July 2019; pp. 43-44.

19. Trauth, E.M. The Choice of Qualitative Methods in IS Research. In Qualitative Research in IS; IGI Global: Hershey, PA, USA, 2011; pp. 1-19.

20. Rourke, L.; Anderson, T. Validity in quantitative content analysis. Educ. Technol. Res. Dev. 2004, 52, 5-18. [CrossRef]

21. Kruse, J.; Lenger, A. Zur aktuellen Bedeutung von qualitativen Forschungsmethoden in der deutschen VolkswirtschaftslehreEine programmatische Exploration. Z. Qual. Forsch. 2014, 14, 105-138. [CrossRef]

22. Parker, E.B.; Short, J.; Williams, E.; Christie, B. The Social Psychology of Telecommunications. Contemp. Sociol. A J. Rev. 1978, 7, 32. [CrossRef]

23. Wilson, E.O. Biophilia; Harvard University Press: Cambridge, MA, USA, 1984.

24. Shimp, T.A.; Sharma, S. Consumer Ethnocentrism: Construction and Validation of the CETSCALE. J. Mark. Res. 1987, 24, 280-289. [CrossRef]

25. Hassanein, K.; Head, M. The Impact of Infusing Social Presence in the Web Interface: An Investigation Across Product Types. Int. J. Electron. Commer. 2005, 10, 31-55. [CrossRef]

26. Kim, M.; Lennon, S. The effects of visual and verbal information on attitudes and purchase intentions in internet shopping. Psychol. Mark. 2008, 25, 146-178. [CrossRef]

27. Riva, G.; Mantovani, F.; Waterworth, E.L.; Waterworth, J.A. Intention, Action, Self and Other: An Evolutionary Model of Presence. In Immersed in Media; Lombard, M., Biocca, F., Freeman, J., IJsselsteijn, W., Schaevitz, R., Eds.; Springer International Publishing: Cham, Switzerland, 2015; pp. 73-99.

28. Lee, K.M. Why Presence Occurs: Evolutionary Psychology, Media Equation, and Presence. Presence Teleoperators Virtual Environ. 2004, 13, 494-505. [CrossRef]

29. Aristotle. The Politics; Sir Baker, E., Ed.; Oxford University Press: Oxford, UK, 2009.

30. Ulrich, R.S. Biophilia, Biophobia, and Natural Landscapes. In The Biophilia Hypothesis; Kellert, S.R., Wilson, E.O., Eds.; Island Press: Washington, DC, USA, 1993; pp. 73-137.

31. Kaplan, R.; Kaplan, S. The Experience of Nature: A Psychological Perspective; Cambridge University Press: Cambridge, UK, 1989.

32. Driedger, L.; Berghe, P.L.V.D. The Ethnic Phenomenon. Can. J. Sociol. Cah. Can. Sociol. 1984, 9, 120. [CrossRef]

33. Forman, C.; van Zeebroeck, N. Digital Technology Adoption and Knowledge Flows within Firms: Can the Internet Overcome Geographic and Technological Distance? Res. Policy 2018, 48, 103697. [CrossRef]

34. Vartiainen, T.; Siponen, M.; Moody, G.D. Gray-Area Phenomenon in Information Systems Development: A Call for Research. In Proceedings of the Pacific Asia Conference on Information Systems (PACIS), Brisbane, Australia, 7-11 July $2011 ;$ p. 198.

35. Yazdanifard, R.; Khalid Obeidy, W.; Fadzilah, W.; Yusoff, W.; Babaei, H.R. Social Networks and Microblogging-The Emerging Marketing Trends and Tools of the Twenty-First Century. In Proceedings of the International Conference on Computer Communication and Management, Sydney, Australia, 13-14 May 2011; Volume 5, pp. 577-581.

36. Watson, G.F.; Worm, S.; Palmatier, R.W.; Ganesan, S. The Evolution of Marketing Channels: Trends and Research Directions. J. Retail. 2015, 91, 546-568. [CrossRef]

37. Borowski, P.F. Innovation strategy on the example of companies using bamboo. J. Innov. Entrep. 2021, 10, 1-17. [CrossRef]

38. Stadtwerke in Deutschland Liste der Deutschen Stadtwerke. Available online: https://stadtwerke-in-deutschland.de (accessed on 5 February 2020).

39. Bell, P. Content Analysis of Visual Images. In The Handbook of Visual Analysis; von Leeuwen, T., Jewitt, C., Eds.; Sage Publications Ltd.: London, UK, 2001; pp. 10-34.

40. Callahan, E. Cultural Similarities and Differences in the Design of University Web sites. J. Comput. Commun. 2005, 11, 239-273. [CrossRef]

41. Xi, Y.; Zhuang, Y.; Huang, W.; She, C.; Zhang, Z. The Quality Assessment and Content Analysis of Corporate Websites in China: An Empirical Study. Int. J. Inf. Technol. Decis. Mak. 2007, 6, 389-405. [CrossRef] 
42. Vilnai-Yavetz, I.; Tifferet, S. Promoting service brands via the Internet. Serv. Ind. J. 2013, 33, 1544-1563. [CrossRef]

43. Cohen, J. A Coefficient of Agreement for Nominal Scales. Educ. Psychol. Meas. 1960, 20, 37-46. [CrossRef]

44. Viera, A.J.; Garrett, J.M. Understanding interobserver agreement: The kappa statistic. Fam. Med. 2005, 37, 360-363.

45. Braun, V.; Clarke, V. Using Thematic Analysis in Psychology. Qual. Res. Psychol. 2006, 3, 77-101. [CrossRef]

46. Hongladarom, S. Global culture, local cultures and the internet: The Thai example. AI Soc. 1999, 13, 389-401. [CrossRef]

47. $\mathrm{Hu}, \mathrm{W} . ;$ Batte, M.T.; Woods, T.; Ernst, S. Consumer preferences for local production and other value-added label claims for a processed food product. Eur. Rev. Agric. Econ. 2011, 39, 489-510. [CrossRef]

48. Kneafsey, M.; Ilbery, B. Regional Images and the Promotion of Speciality Food and Drink in the West Country. Geography 2001, 86, 131-140.

49. Bruwer, J.; Johnson, R. Place-based marketing and regional branding strategy perspectives in the California wine industry. J. Consum. Mark. 2010, 27, 5-16. [CrossRef]

50. Luceri, B.; Latusi, S.; Zerbini, C. Product versus region of origin: Which wins in consumer persuasion? Br. Food J. 2016, 118, 2157-2170. [CrossRef]

51. Hamid, M.A. Analysis of visual presentation of cultural dimensions: Culture demonstrated by pictures on homepages of universities in Pakistan. J. Mark. Commun. 2016, 23, 592-613. [CrossRef]

52. Menzel, T.; Teubner, T. Green energy platform economics-Understanding platformization and sustainabilization in the energy sector. Int. J. Energy Sect. Manag. 2021, forthcoming. [CrossRef]

53. Weinhardt, C.; Mengelkamp, E.; Cramer, W.; Hambridge, S.; Hobert, A.; Kremers, E.; Otter, W.; Pinson, P.; Tiefenbeck, V.; Zade, M. How Far along Are Local Energy Markets in the DACH+ Region? A Comparative Market Engineering Approach. In Proceedings of the e-Energy 2019, Phoenix, AZ, USA, 25-28 June 2019; pp. 544-549.

54. Matzner, M.; Chasin, F.; von Hoffen, M.; Plenter, F.; Becker, J. Designing a Peer-to-Peer Sharing Service as Fuel for the Development of the Electric Vehicle Charging Infrastructure. In Proceedings of the Hawaii International Conference on System Sciences (HICSS) 2016, New York, NY, USA 15-17 March 2016; pp. 1587-1595.

55. Hoang, D.T.; Wang, P.; Niyato, D.; Hossain, E. Charging and Discharging of Plug-In Electric Vehicles (PEVs) in Vehicle-to-Grid (V2G) Systems: A Cyber Insurance-Based Model. IEEE Access 2017, 5, 732-754. [CrossRef]

56. Hesse, M.; Dann, D.; Braesemann, F.; Teubner, T. Understanding the Platform Economy: Signals, Trust, and Social Interaction. In Proceedings of the Hawaii International Conference on System Sciences (HICSS), Maui, HI, USA, 7-10 January 2020; pp. 1-10.

57. Söllner, M.; Hoffmann, A.; Leimeister, J.M. Why different trust relationships matter for information systems users. Eur. J. Inf. Syst. 2016, 25, 274-287. [CrossRef]

58. Stenner, K.; Frederiks, E.R.; Hobman, E.V.; Cook, S. Willingness to participate in direct load control: The role of consumer distrust. Appl. Energy 2017, 189, 76-88. [CrossRef]

59. Ableitner, L.; Tiefenbeck, V.; Meeuw, A.; Wörner, A.; Fleisch, E.; Wortmann, F. User behavior in a real-world peer-to-peer electricity market. Appl. Energy 2020, 270, 115061. [CrossRef]

60. Delmas, M.A.; Burbano, V.C. The Drivers of Greenwashing. Calif. Manag. Rev. 2011, 54, 64-87. [CrossRef]

61. Regionale Energiewerke. Available online: https://regionale-energiewerke.de/home (accessed on 10 November 2020).

62. Enyway. Available online: https://www.enyway.com/de/power (accessed on 10 November 2020).

63. Gutierrez, A.M.J.; Chiu, A.S.F.; Seva, R. A Proposed Framework on the Affective Design of Eco-Product Labels. Sustainability 2020, 12, 3234. [CrossRef] 